\title{
Variability of Atlantic Ocean heat transport and its effects on the atmosphere
}

\author{
Buwen Dong and Rowan T. Sutton \\ Centre for Global Atmospheric Modelling, Department of Meteorology, \\ University of Reading, U.K.
}

\begin{abstract}
The variability of the Atlantic meridional Ocean Heat Transport (OHT) has been diagnosed from a simulation of a coupled ocean-atmosphere general circulation model, and the mechanisms responsible for this variability have been elucidated. It has been demonstrated that the interannual variability in Atlantic OHT is dominated by windstress-driven Ekman fluctuations. In contrast, the decadal and multidecadal variability is associated with the fluctuations of the Thermohaline Circulation (THC), driven by the fluctuations in deep convection over the Greenland-Iceland-Norwegian (GIN) Sea. The fluctuations of OHT induce Ocean Heat Content (OHC), and Sea Surface Temperature (SST) anomalies over the tropical and subtropical North Atlantic. The SST anomalies, in turn, have an impact on the atmosphere. The lead-lag relationships between the fluctuations of THC-related OHT and those of OHC and SST raise the possibility that a knowledge of OHT fluctuations could be used to predict variations in Atlantic Sea surface temperatures, and perhaps aspects of climate, several years in advance. A comparison of results from a second, independent, coupled model simulation is also presented, and similar conclusions reached.
\end{abstract}

Key words climate variability - North Atlantic Oscillation (NAO) - Ocean Heat Transport (OHT) Sea Surface Temperature (SST) - Thermohaline Circulation (THC)

\section{Introduction}

The fact that the ocean and atmosphere transport heat polewards is one of the most fundamental features of the climate system. Substantial changes in these heat transports would inevitably provoke major climate change (e.g., Manabe and Stouffer, 1995, 1999). Yet the

Mailing address: Dr. Rowan Sutton, Centre for Global Atmospheric Modelling, Department of Meteorology, University of Reading, PO Box 243, Earley Gate, Reading RG6 6BB, U.K.; email: R.Sutton@ reading.ac.uk processes that regulate poleward heat transport, and control its variability, are poorly understood.

A major aim of the SINTEX project was to advance understanding of the processes that determine the variability of heat transport in the Atlantic Ocean, and its effects on the atmosphere. The Atlantic Ocean plays a particularly important role in global heat transport. Whereas the total ocean heat transport is poleward in both hemispheres, the heat transport in the Atlantic is northward even in the Southern Hemisphere (e.g., Peixoto and Oort, 1993). This surprising situation is a consequence of the thermohaline circulation, in which deep water formation in the North Atlantic plays a key role. An implication of this situation is that major changes in the North Atlantic thermohaline circulation could have a substantial global impact.

Efforts to understand the variability in Atlantic Ocean heat transport are hindered by a 
lack of sufficient ocean observations. Consequently it is necessary to turn to models. In this paper, work with a version of the U.K. Hadley Centre climate model HadCM3 is reported. This model requires no flux corrections to maintain a stable climate and is thus an excellent tool for studying heat transports and their variability.

The structure of the paper is as follows. In Section 2 the model and simulation are described. The variability of Atlantic Ocean heat transport, and its effects on the atmosphere, are discussed in Section 3. In Section 4 comparisons are made with a second coupled model that was developed as part of the SINTEX project. Summary and conclusions are in Section 5.

\section{Description of model simulation}

The principal model we use is a version of the United Kingdom Hadley Centre global coupled ocean atmosphere general circulation model known as HadCM3, described in Gordon et al. (2000). The atmospheric model component in HadCM3 is a version of the United Kingdom Meteorological Office (UKMO) unified forecast and climate model run with a horizontal grid spacing of $2.5^{\circ} \times 3.75^{\circ}$ and 19 vertical levels using a hybrid vertical coordinate. The oceanic component of the model is a 20 level version of the Cox $(1984)$ model on a $1.25^{\circ} \times 1.25^{\circ}$ latitudelongitude grid with a sea ice model using a simple thermodynamic scheme and containing parameterizations of ice drift and leads (Cattle and Crossley, 1995). The model does not require flux corrections to maintain a stable climate. The mean climate and its stability in a 1000 year control simulation are discussed in Gordon et al. (2000).

We modified the model in such a way as to restrict atmosphere-ocean interactions to regions outside the tropical Pacific and tropical Indian Ocean. Over the tropical Pacific and tropical Indian Ocean, the SSTs were relaxed to the monthly mean HadCM3 climatology with a time scale of 2.5 days. The main effect of this relaxation is to eliminate the El Niño-Southern Oscillation (ENSO) phenomenon in the simulation. This allows us to study ocean-atmosphere interactions in the Atlantic basin without inter- ference from the tropical Pacific and tropical Indian Ocean. We performed a control integration of 100 years duration employing this relaxation. The initial state was taken from a 1000 year control simulation of the globally coupled model. The coupled model reproduces the principle features of the North Atlantic Ocean circulations in a satisfying manner (Dong and Sutton, 2002a,b). The dominant convective region occurs over the northeast North Atlantic, over the Greenland, Iceland, and Norwegian (GIN) Sea, where the annual mean mixed layer depth reaches a maximum of about $200 \mathrm{~m}$ while the mixed layer depth in the winter is over $500 \mathrm{~m}$.

\section{Results}

\subsection{Variability of Atlantic Meridional Ocean heat transport}

The annual mean Atlantic OHT anomalies are given in fig. 1 for the specially configured HadCM3 simulation. The heat transport anomalies range from $-0.2 \mathrm{PW}\left(10^{15} \mathrm{~W}\right)$ to $0.2 \mathrm{PW}$. These correspond to about $20 \%$ to $30 \%$ of the model climatological mean heat transport (1.18 $\mathrm{PW}$ at $24.4^{\circ} \mathrm{N}$ ) depending on latitude. There are several interesting aspects of the OHT variations. First, the variations in the tropics and subtropics show a high degree of coherence with latitude. Secondly, the dominant frequency differs between low latitudes and mid-to-high latitudes. In low latitudes, most of the variability is on multi-annual timescales. In mid-to-high latitudes, lower frequency variations predominate.

\subsection{Mechanisms of the Atlantic Ocean heat transport}

Fluctuations in the OHT may arise from processes that are internal to the ocean, or in response to atmospheric fluctuations. The latter can arise from windstress-driven variations in Ekman transport, from density-driven variations in the Thermohaline Circulation (THC) and from windstress curl-driven variations in the gyre circulation. To identify the different contributions 


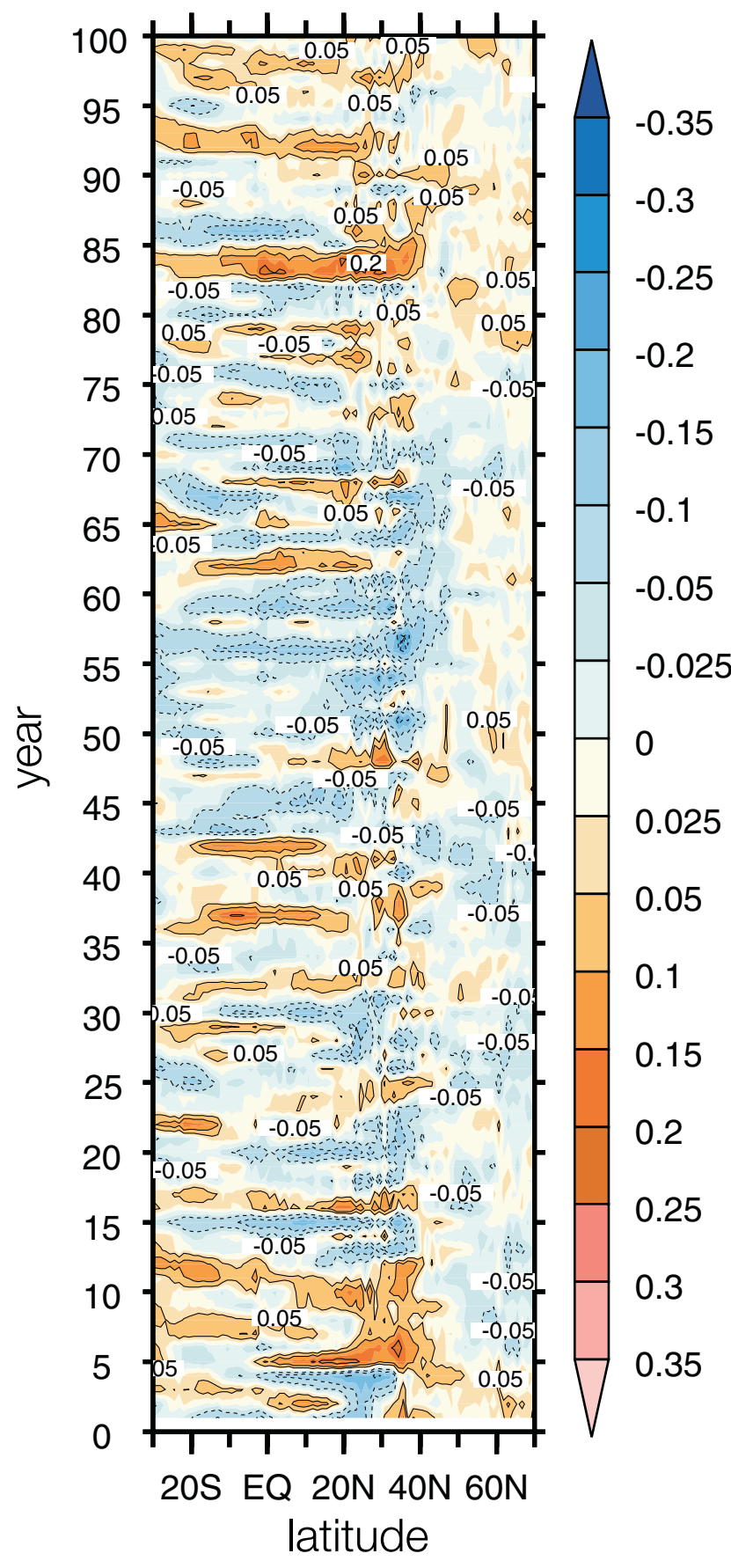

Fig. 1. Latitude-time evolution of the ocean heat transport anomalies (PW: $10^{15} \mathrm{~W}$ ) in the Atlantic for the HadCM3 simulation. Positive anomalies are in full lines and negative ones in dashed lines.

to the OHT variability, we use a principal component analysis. Dong and Sutton (2001) showed that the dominant mode (EOF1) of the Atlantic OHT, which explains $50.3 \%$ of interannual variance, is associated with wind-driven fluctua- tions in Ekman transport. In this paper we focus on the lower frequency variability in Atlantic OHT.

Figure 2a-e shows EOF1 of low pass filtered (5 years running mean) OHT and the associated PC1 for the HadCM3 simulation. This mode explains $55.6 \%$ of the low frequency variance. It reaches peak amplitude around $30^{\circ}-40^{\circ} \mathrm{N}$ (where the mean meridional temperature gradients are greatest), decaying rapidly to the north of this latitude and more gradually to the south. PC1 indicates that the timescale of variability for this mode is decadal-to-multi-decadal. The regression pattern of the mean meridional overturning circulation (MOC) to $\mathrm{PC} 1$ of low frequency OHT is shown in fig. 2c. It is characterized by a single cell extending south from $70^{\circ} \mathrm{N}$ and reaching well across the equator. The vertical structure is baroclinic. This regression pattern is very similar to EOF2 (20.4\% of total variance, not shown) of the low-pass filtered MOC (pattern correlation is 0.87 ). Figure $2 b$ shows that the associated principal components are also highly correlated. This suggests that low frequency variations of the OHT are associated with the Atlantic THC variability. EOF1 of the low-pass filtered MOC, which explains $41.0 \%$ of low frequency variance, is associated with a trend in MOC. This mode makes only a minor contribution to the OHT variability. In fact, PC1 of MOC is highly correlated with PC3 of OHT with OHT EOF3 accounting for $8.3 \%$ of low frequency OHT variance. We, therefore, focus on the PC2 of MOC and PC1 of OHT, and their associated climate variability.

Figure $2 \mathrm{~d}$ shows the regression of upper ocean density onto PC2 of the MOC. It is clear that density variations over the Greenland-Iceland-Norwegian (GIN) Sea region are correlated with fluctuations in the MOC, such that a positive density anomaly is associated with a maximum in the MOC. The positive density anomalies extend from the surface to about $1000 \mathrm{~m}$ with weak negative density anomalies from about $1000 \mathrm{~m}$ to $3000 \mathrm{~m}$ (not shown), thereby reducing the vertical stability of the water column, enhancing the deep convection rate, and driving a stronger MOC. The relationship between the MOC and density anomalies over the GIN sea is 
(a)

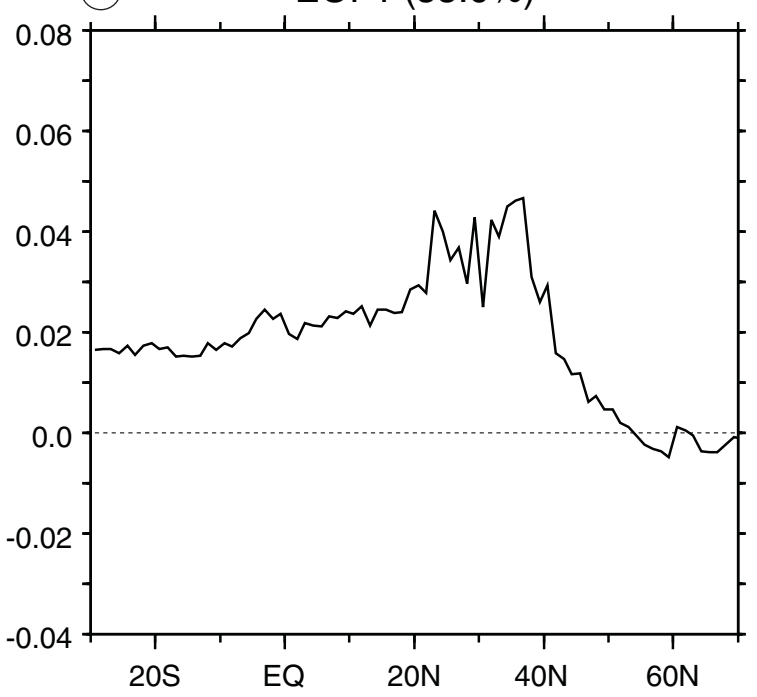

(C)

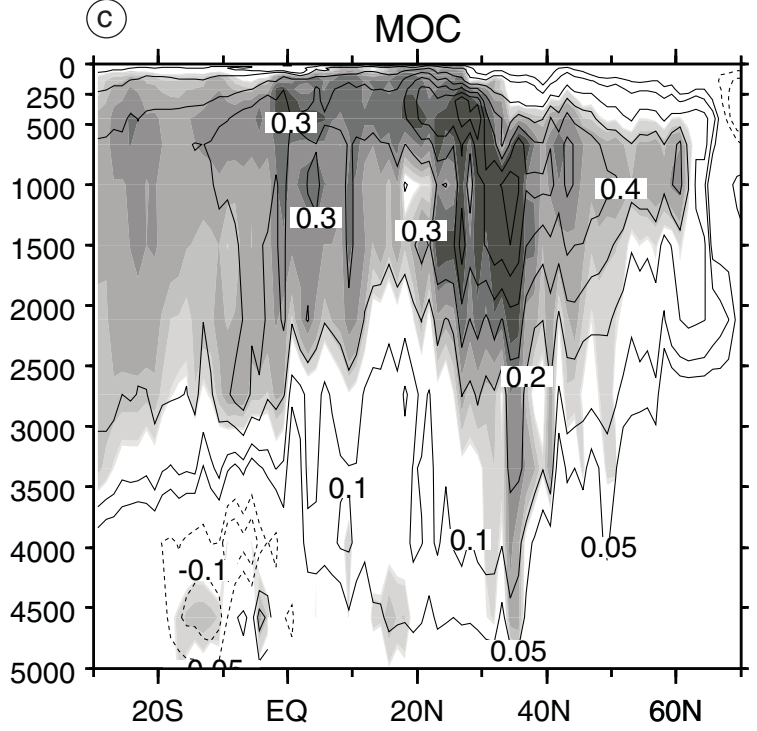

(e) MOC PC2 and density index

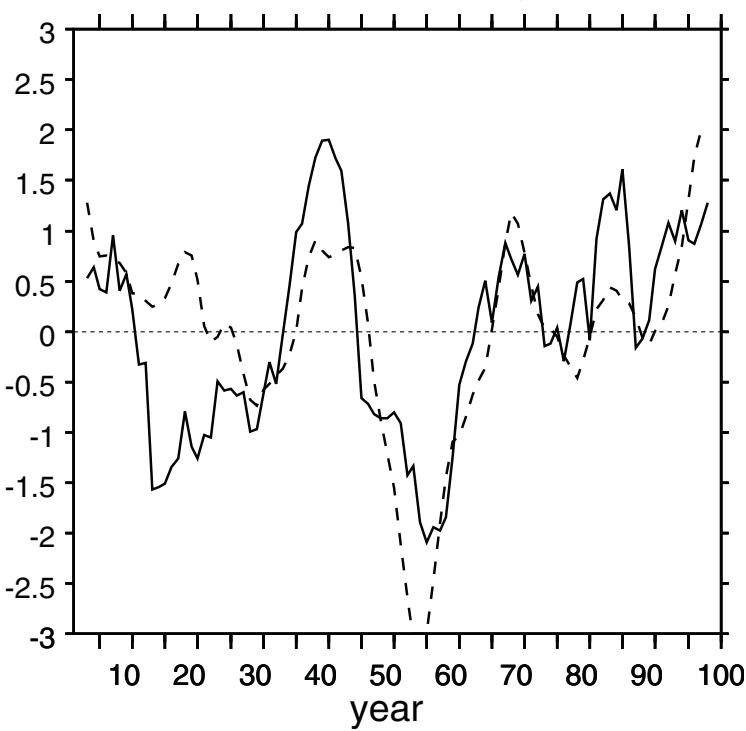

(b) $\mathrm{PC} 1(\mathrm{OHT})$ and $\mathrm{PC} 2(\mathrm{MOC})$
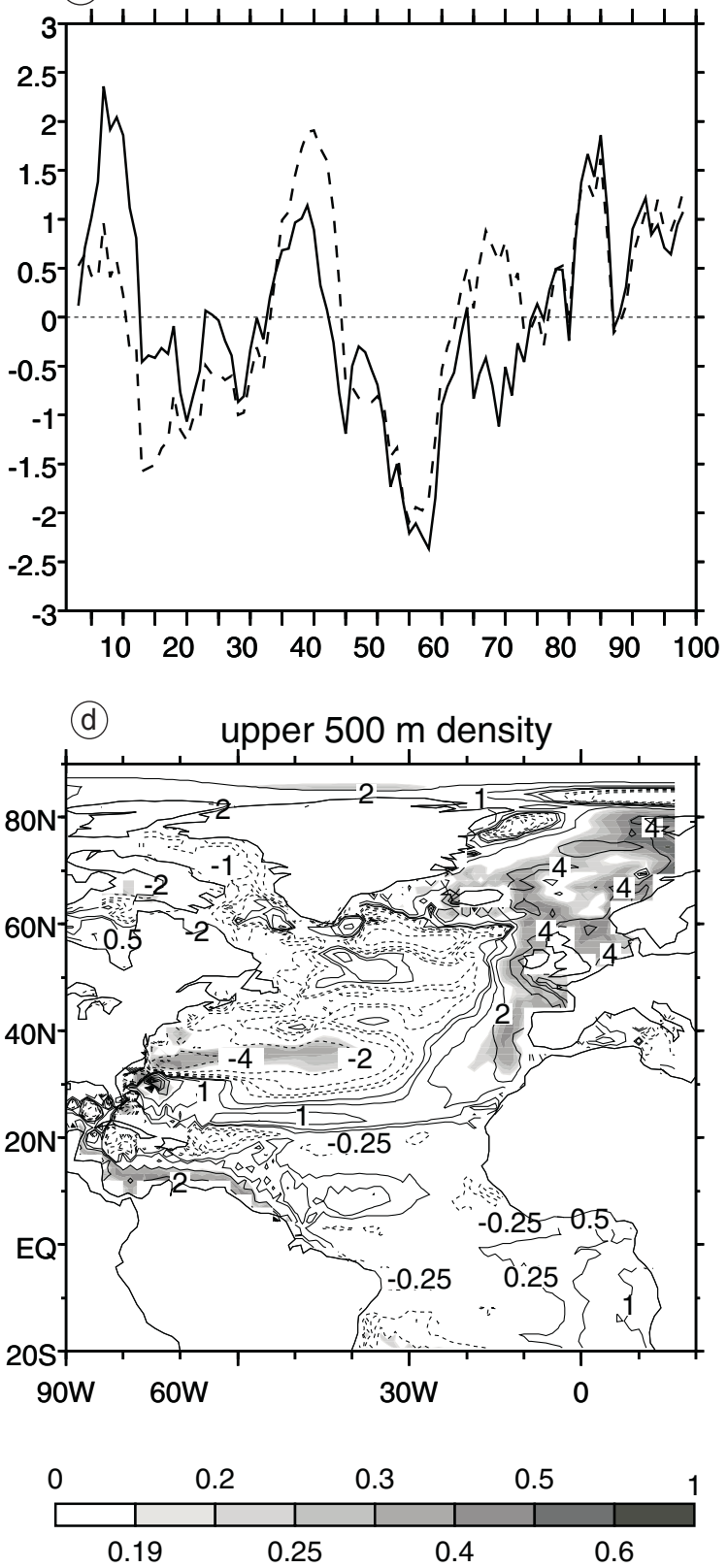

Fig. 2a-e. a) EOF1 (PW: 10 ${ }^{15} \mathrm{~W}$ ), and (b) PC1 (solid line) of low frequency OHT for the HadCM3 simulation. Panel (b) also shows (dashed line) PC2 of low frequency MOC. c) Regression pattern of the MOC at lag 0 on PC1 of low frequency ocean heat transport (unit: Sv per unit of PC1 of OHT). d) Regression coefficients of the upper ocean $(500 \mathrm{~m})$ density $\left(10^{-5} \mathrm{~g}\right.$ $\mathrm{cm}^{-3}$ ) to PC2 of the MOC at lag 0. e) Normalized time series of PC2 of the MOC and the density index defined over the deep convection region. Shading scale in (c) and (d) indicates explained local variance. 
further illustrated by fig. 2e, which shows the normalized time series of the PC2 of the MOC and density index, which is defined as averaged density over the GIN sea $\left(60^{\circ} \mathrm{N}-80^{\circ} \mathrm{N}, 20^{\circ} \mathrm{W}\right.$ $\left.15^{\circ} \mathrm{E}\right)$. In general, the two time series fluctuate in phase except in first 25 years. This may be due to the spin-up process of the model. The two time series are highly correlated with a coefficient 0.66 . The correlation increases to 0.83 if the last 75-years data are used.

\subsection{Relationships between variability in OHT, ocean heat content and SST}

In the previous section, we have shown that in addition to the interannual fluctuations, the Atlantic OHT in the model simulation also exhibits decadal variability. It has long been suspected that the changes in the oceanic THC and associated OHT may have been an important factor in the climate fluctuations. In this section and the next, we investigate how the ocean and atmosphere respond to fluctuations in the THC and associated OHT.

To show the oceanic response to the THC fluctuations, the lagged linear regressions of the annual mean low frequency Ocean Heat Content (OHC) and SST to the PC2 of the low frequency MOC have been calculated. Shown in fig. 3 are the regression maps at different lags. Similar regressions against PC1 of low frequency OHT have been performed and the results are very similar to those shown in fig. 3. At lag 0 , the phase of maximum THC and OHT, there are positive OHC anomalies over the Gulf Stream region, with negative anomalies to the north and weak negative anomalies in the tropical and subtropical Atlantic. As time advances the positive anomalies in the Gulf Stream region and the negative anomalies in the northern subtropical Atlantic grow in strength. The positive anomalies are then seen to propagate northeastward, approximately along the path of the North Atlantic Current. By lag 8 a welldeveloped dipolar pattern of OHC anomalies is seen.

The major features of the OHC evolution could be anticipated from fig. 2a. The structure of the EOF suggests that convergence of the northward heat transport in the north Atlantic (north of about $40^{\circ} \mathrm{N}$ ) should be associated with divergence of the heat transport in the subtropical Atlantic (and vice versa). Thus, following a maximum in the THC there is a tendency to build up heat in the North Atlantic, and to evacuate it from the subtropical Atlantic - which leads to the dipolar pattern in OHC. The regression patterns for SST (fig. 3, right column) show that the $\mathrm{OHC}$ anomalies are also manifest at the surface, suggesting the possibility of impacts on the atmosphere. Note finally that the northeastward propagation of OHC and SST anomalies along the path of the North Atlantic Current is in line with the SST features identified in the observational study of Sutton and Allen (1997). The characteristics of the propagation in the model are further analysed by Dong and Sutton (2002a).

\subsection{The impact of Atlantic OHT variability on the atmosphere}

In Section 3.3, it was seen that the low frequency fluctuations in Atlantic OHT induce significant SST anomalies. Do these SST anomalies have significant effects on the atmosphere? To investigate this question lagged regressions of atmospheric variables to the PC2 of the MOC were performed. Figure 4a-c shows the regression maps of SST, mean sea level pressure (mslp), and surface wind 4 years after the maximum of THC and associated OHT. The regression patterns are similar to fig. 4a-c when the PC2 of the MOC leads by 2-6 years, with regressions reaching a maximum at lag 4 . Figure 4a indicates that the SST pattern is characterized by a tripole with positive anomalies over the Gulf Stream region and negative anomalies to the north and south. The mslp and surface wind regression patterns (fig. $4 \mathrm{~b}, \mathrm{c}$ ) have a positive projection on the well-known North Atlantic Oscillation (NAO, Hurrell, 1995). The height field (not shown) indicates that the tropical response is baroclinic while extra-tropical response is equivalent barotropic. In the tropics, the cross-Equator SST gradient induces a southward shift of ITCZ as indicated by the precipitation regression pattern (not shown). 

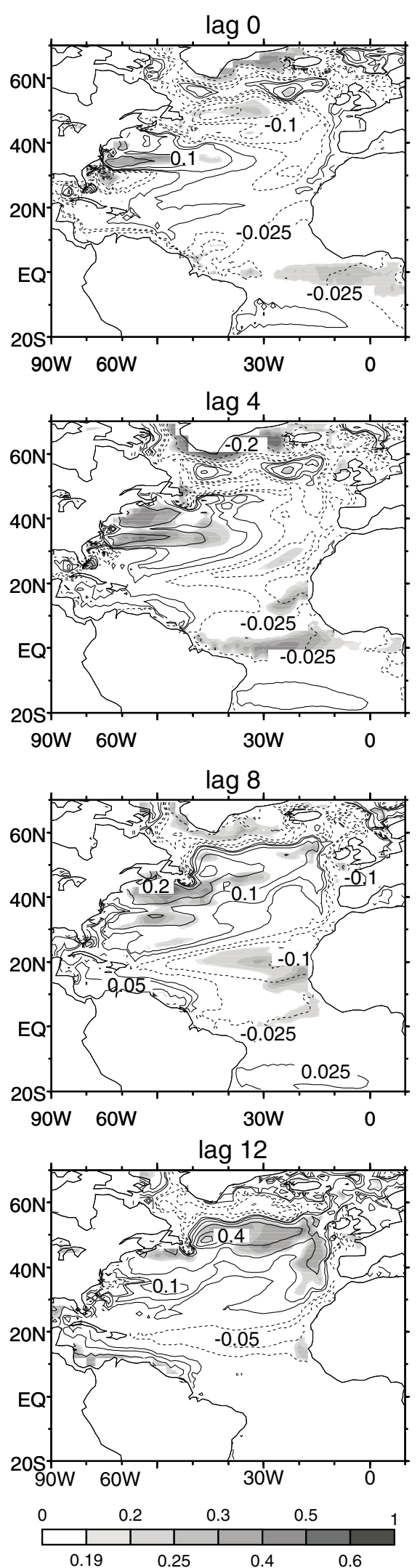
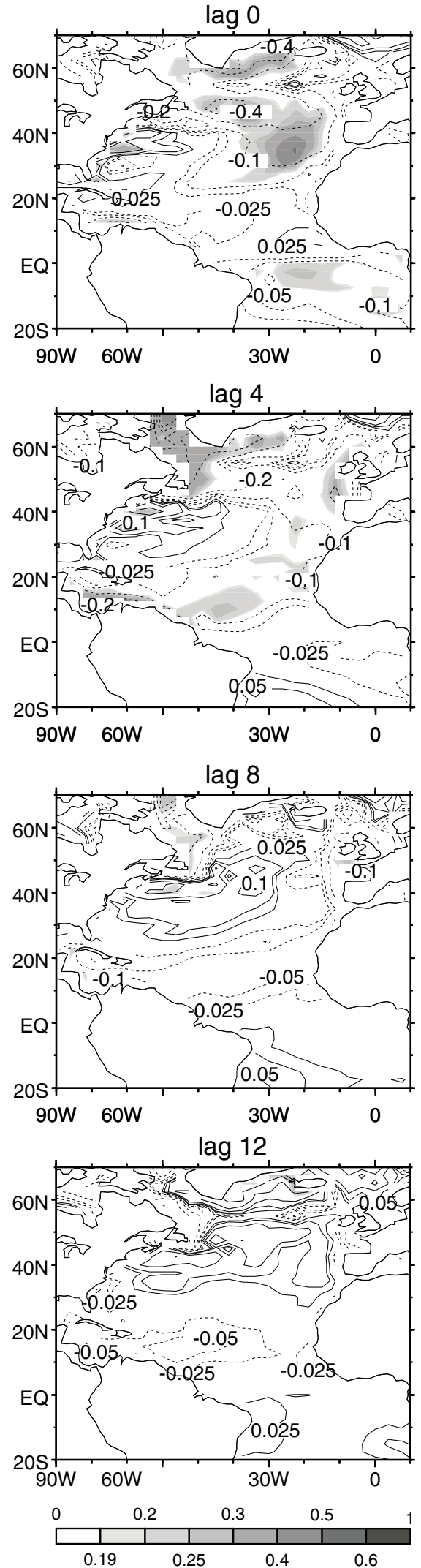

Fig. 3. Regression coefficients of the annual mean ocean heat content (left) and sea surface temperature (right) to the PC2 of the MOC at various lags for the HadCM3 simulation. Positive lags mean the MOC leading. Units are in ${ }^{\circ} \mathrm{C}$ per unit $\mathrm{PC} 2$ of the MOC. Shading scale indicates explained local variance. 

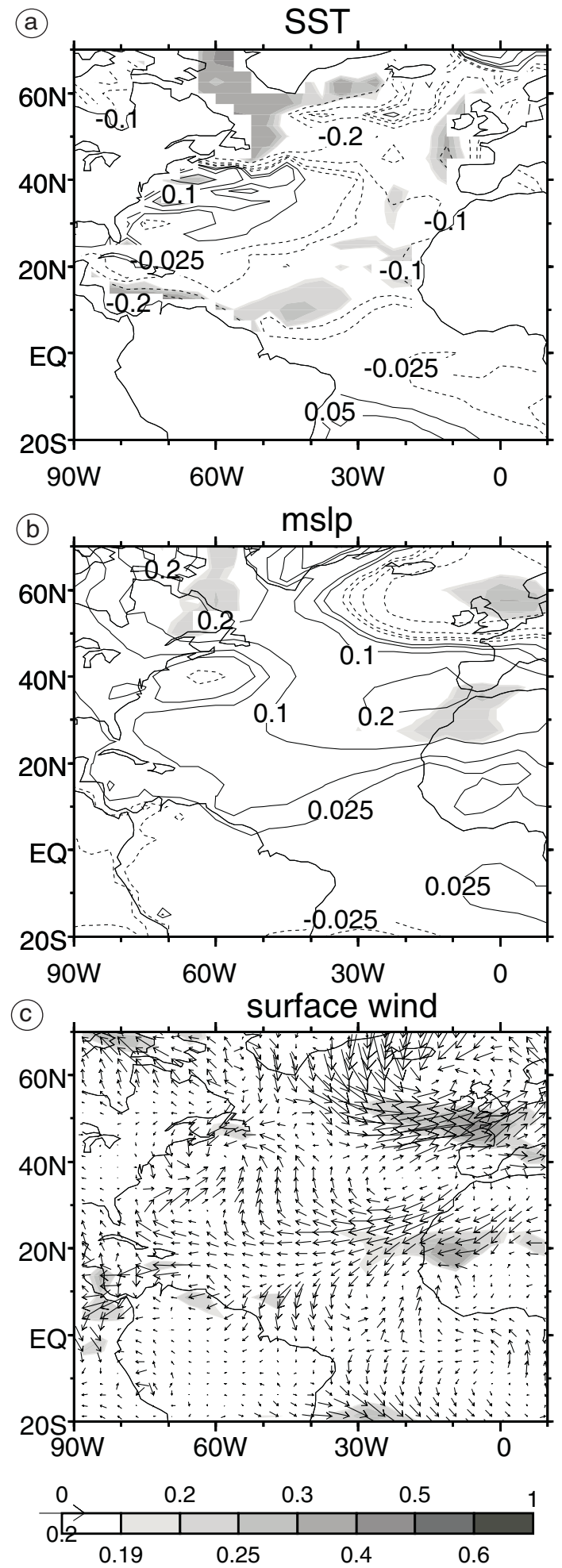

Fig. 4a-c. The regression patterns of low frequency annual sea surface temperature (a), mean sea level pressure (b), and surface wind (c) to the PC2 of the MOC when MOC leading by 4 years for the HadCM3 simulation. Units are in ${ }^{\circ} \mathrm{C}, \mathrm{hPa}$, and $\mathrm{m} \mathrm{s}^{-1}$ per unit PC2 of the MOC. Shading scale indicates explained local variance.
Sutton et al. (2001) showed, using idealised experiments with the atmospheric component of HadCM3, that an atmospheric pattern similar to that shown in fig. 4b,c can be induced in response to an SST tripole pattern similar to that shown in fig. 4a. They showed further that changes in tropical convection, over South America and in the ITCZ, play a key role. This anomalous convection results in anomalous heating and triggers the extratropical equivalent barotropic response through Rossby waves (Sardeshmukh and Hoskins, 1988). Further experiments showed that forcing of this response is primarily by the tropical SST anomalies, although the midlatitude anomalies also make a small contribution.

Putting together the results of Sutton et al. (2001) with the results from this coupled model study clearly suggests that THC-related fluctuations in the Atlantic Ocean heat transport can impact the atmosphere, in particular by modulating SST in the Northern tropical Atlantic. More detailed study of the role of ocean dynamics in North Atlantic decadal climate variability in our model simulation will be reported elsewhere (Dong and Sutton, 2002b).

\section{Comparison with the ECHAM4T30/OPA simulation}

In this section, we compare the results from our HadCM3 simulation with results from another SINTEX model: the ECHAM4T30/OPA coupled GCM. We analyse a 200-year simulation of this model. Adetailed description of the model, and an account of the ENSO variability in this simulation, is given by Guilyardi et al. (2001). Because the simulation is subject to some climate drift, a 20-year running mean was removed prior to analysis to eliminate very low frequency variability.

The annual mean Atlantic OHT anomalies from the ECHAM4T30/OPA simulation are shown in fig. 5. The heat transport anomalies range from - $0.15 \mathrm{PW}$ to $0.15 \mathrm{PW}$, or about $20 \%$ of the mean heat transport $\left(0.85 \mathrm{PW}\right.$ at $\left.20.4^{\circ} \mathrm{N}\right)$. As in the HadCM3 simulation (fig. 1), the fluctuations of OHT show a high degree of coherence across the equator and in the subtropics. As for the HadCM3 simulation, a principle component 

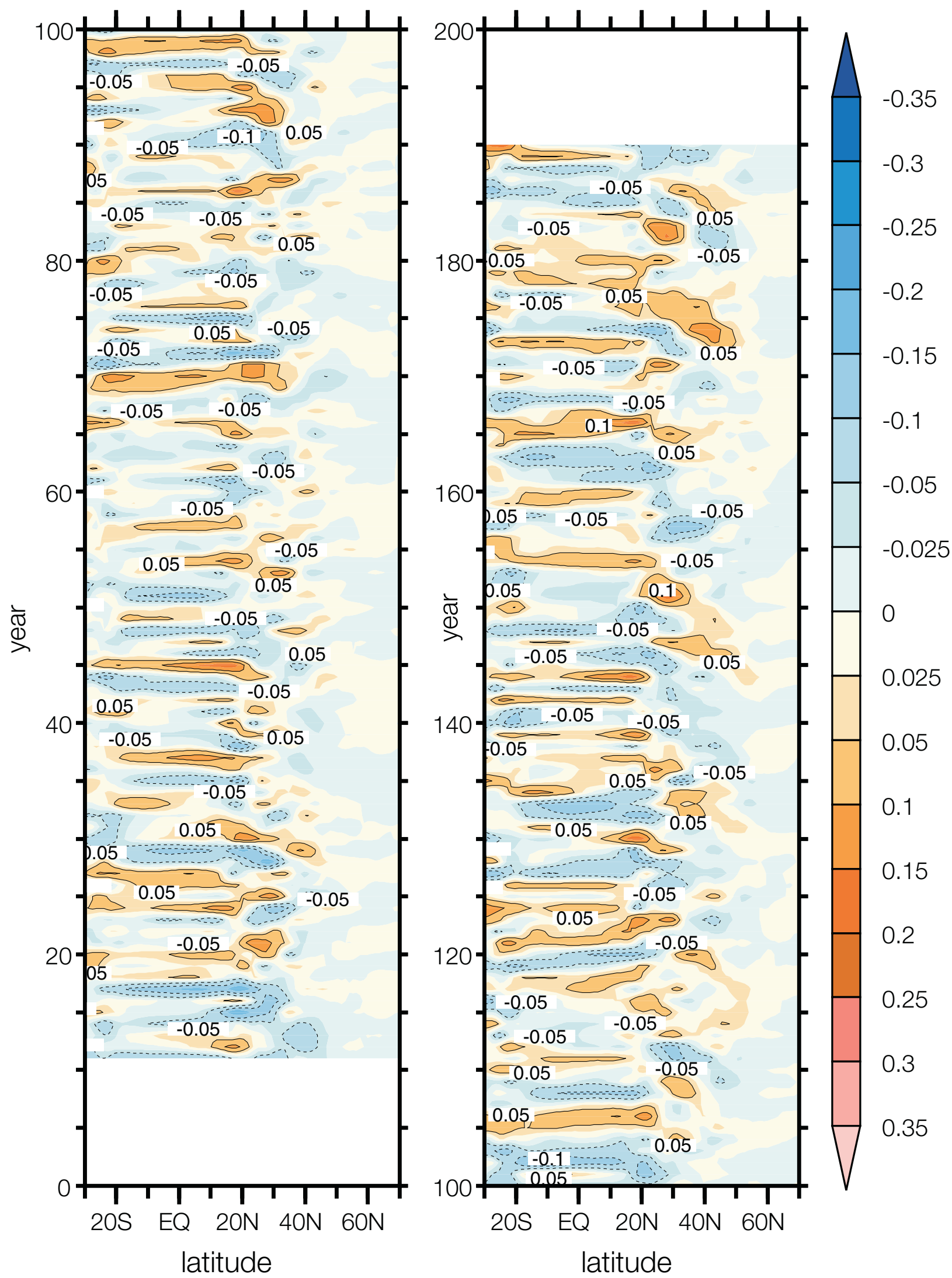

Fig. 5. Latitude-time evolution of the ocean heat transport anomalies (PW: $\left.10^{15} \mathrm{~W}\right)$ in Atlantic for the ECHAM4T30/ OPA simulation. Positive anomalies are in full lines and negative ones in dashed lines. 

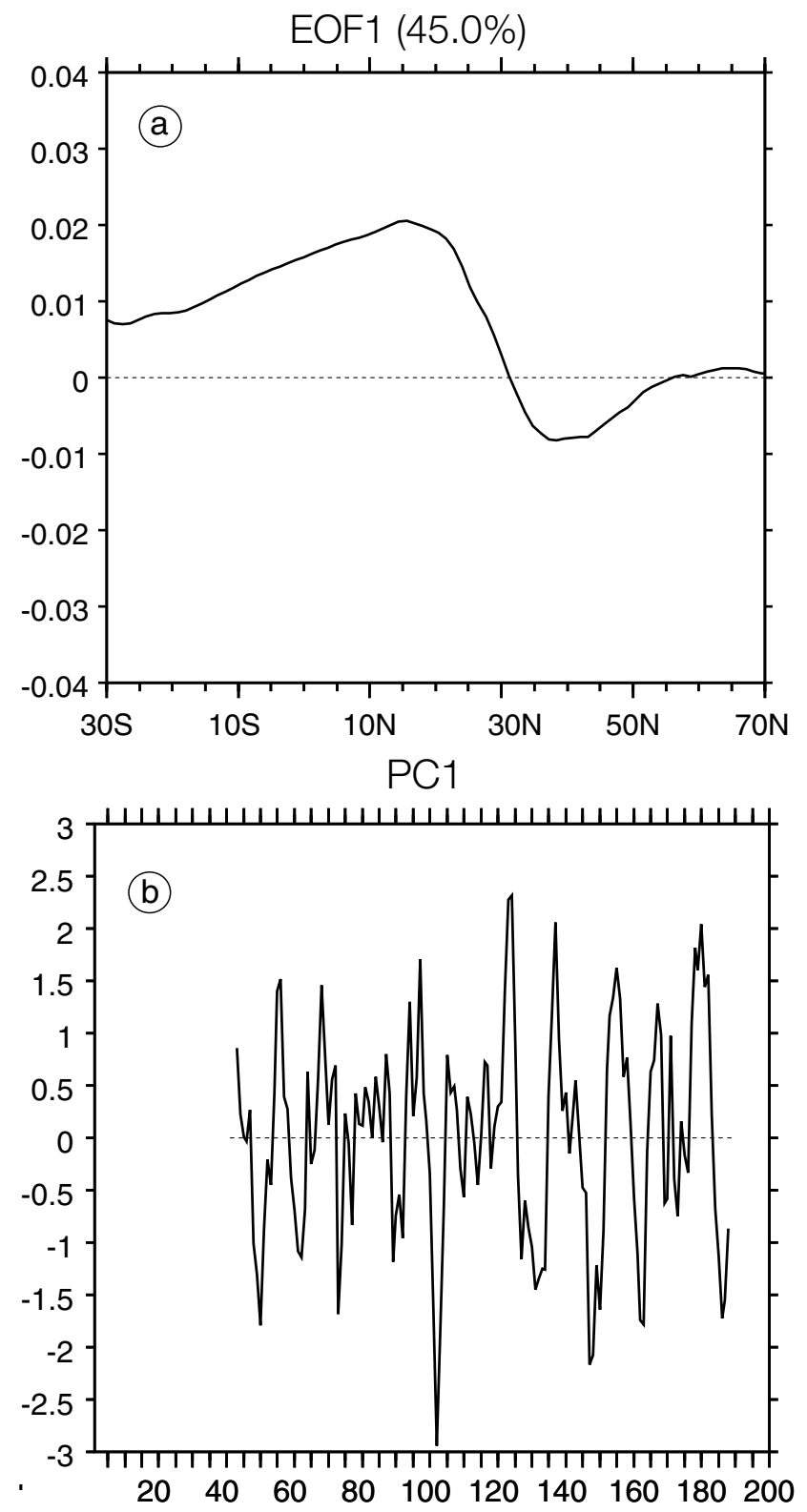

Fig. 6a,b. a) EOF1 (PW: $\left.10^{15} \mathrm{~W}\right)$, and (b) PC1 of low frequency OHT for the ECHAM4T30/OPA simulation.

analysis of the OHT was performed. The dominant mode (not shown) of interannual variability, which explains $49.5 \%$ of interannual variance, is - as in HadCM3 - associated with windstress-driven fluctuations in Ekman transport. The dominant mode of low frequency Atlantic OHT, which explains $45.0 \%$ of the total low frequency variance, is shown in fig. 6a,b. The mode is characterized by anomalous heat transport convergence at about $30^{\circ} \mathrm{N}$. This mode is mainly associated with surface buoyancy flux
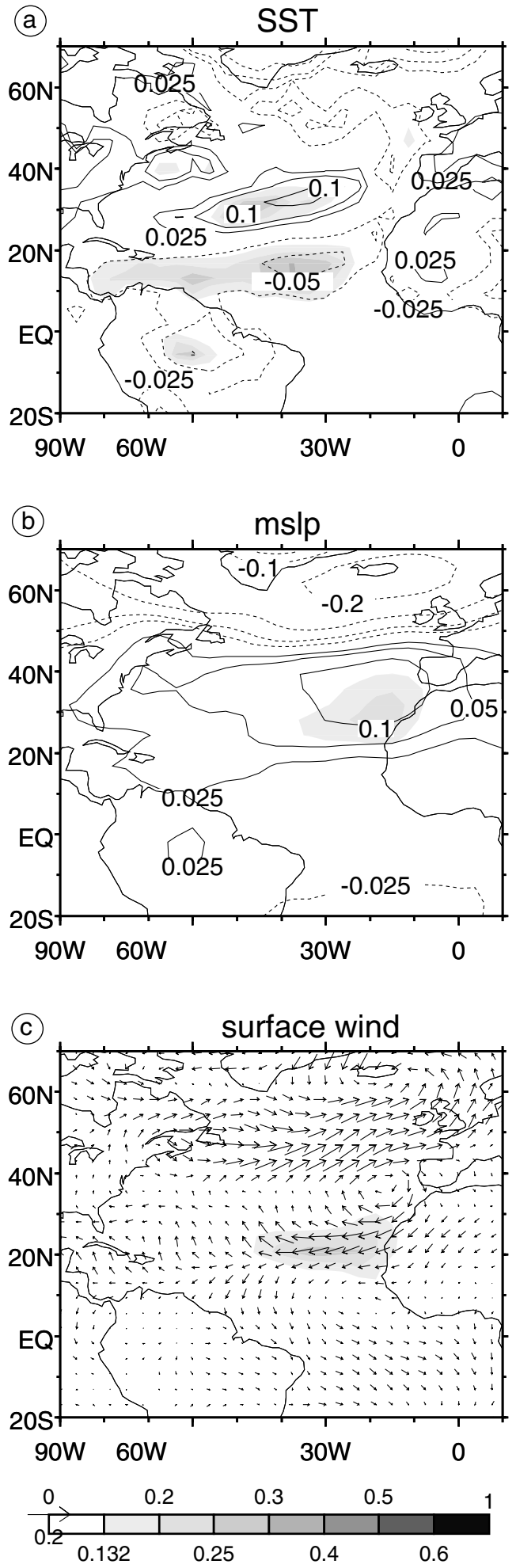

Fig. 7a-c. The regression patterns of low frequency annual sea surface temperature (a), mean sea level pressure (b), and surface wind (c) to the PC1 of the OHT when OHT leading by 2 years for the ECHAM4T30/OPA simulation. Units are in ${ }^{\circ} \mathrm{C}, \mathrm{hPa}$, and $\mathrm{m} \mathrm{s}^{-1}$ per unit PC1 of the OHT. Shading scale indicates ex-plained local variance. 
variability over northeast North Atlantic, but windstress driven Ekman transport fluctuations also play a role (not shown). This implies that the low frequency OHT fluctuations are mainly associated with THC variability. Detailed comparison of the mechanisms responsible for low frequency OHT variability in the two models is beyond the scope of this paper.

The impact of OHT variability on atmosphere in the ECHAM4T30/OPA simulation is illustrated by fig. 7a-c, which shows the regression maps of SST, mslp, and surface wind onto the PC1 of low frequency OHT when the OHT is leading by two years. The SST pattern is characterized by a tripole with positive anomalies over the midlatitudes of North Atlantic and negative anomalies to the north and south. This pattern is consistent with anomalous OHT convergence in midlatitudes and divergence to the south and north (fig. 6a). The mslp regression patterns resemble a positive phase of the North Atlantic Oscillation (NAO). The results here suggest similar behaviour regarding the impact of OHT variability on the atmosphere to that found in the HadCM3 simulation.

\section{Summary and conclusions}

The dominant mechanisms responsible for fluctuations in Atlantic OHT in simulations with two of the SINTEX models have been analysed. We have shown that, in both the simulations, Atlantic OHT exhibits both interannual and decadal variability. The interannual variability of Atlantic OHT is dominated by Ekman transport fluctuations forced by windstress variability. The lower frequency variability of Atlantic OHT is associated with fluctuations in the thermohaline circulation which, in turn, are driven by fluctuations in density and deep convection in the GIN seas region (HadCM3 simulation). Further analysis of the mechanisms responsible for the decadal variability of the THC and its effect on climate in the HadCM3 simulation will be reported elsewhere (Dong and Sutton, 2002b).

The changes in the low frequency OHT result in ocean heat content and surface sea surface temperature variations not only over the highlatitude North Atlantic, but also over the tropical and subtropical North Atlantic. Anomalous negative SST anomalies over the tropical North Atlantic and positive SST anomalies over the midlatitudes of the North Atlantic are associated, respectively, with anomalous OHT divergence and convergence, with the SST fluctuation lagging the OHT fluctuation by a few years. The results suggest that the variations in Atlantic $\mathrm{OHT}$ are playing an important role in the decadal variability of the upper Atlantic Ocean. Negative (positive) SST anomalies in the tropical North Atlantic tend to be associated with the positive (negative) phase of the NAO. Both model simulations suggest a similar response of the North Atlantic climate to the OHT fluctuations with a time lag of a few years. The relationship between the OHT and SST fluctuations raises the possibility that knowledge of OHT fluctuations could be used to predict variations in ocean heat content, and therefore sea surface temperatures, several years in advance. Then, the possibility of climate predictions with multi-year lead times is conceivable.

\section{Acknowledgements}

This work was supported by the EC SINTEX project under contract ENV4-CT98-0714. The computing time was provided by the UGAMP, which is funded by the U.K. Natural Environment Research Council. We like to thank Eric Guilyardi for providing us the ECHAM4T30/ OPA simulation. Comments from an anonymous reviewer are appreciated.

\section{REFERENCES}

Cattle, H. and J. Crossley (1995): Modelling Arctic Climate Change, Phil. Trans. R. Soc. London, A352, 201-213.

Cox, M.D. (1984): A primitive equation, 3 dimensional model of the ocean, GFDL Ocean Group Technical Report n. 1, Princeton NJ, USA, pp. 143.

Dong, B.-W. and R.T. SutTON (2001): The dominant mechanisms of variability in Atlantic Ocean heat transport in a coupled ocean-atmosphere GCM, Geophys. Res. Lett., 28, 2445-2448.

DONG, B.-W. and R.T. SUTTON (2002a): Variability in North Atlantic heat content and heat transport in a coupled ocean-atmosphere GCM, Climate Dyn., 19, 485-497. 
Dong, B.-W. and R.T. SutTon (2002b): Mechanism of Thermohaline Circulation variability and North Atlantic decadal climate variability in a coupled ocean-atmosphere GCM (draft manuscript available from authors).

Gordon, C., C. CoOper, C.A. SEnior, H. BANKS, J.M. GREGORY, T.C. JOHNS, J.F.B. MITCHELL and R.A. WoOD (2000): The simulation of SST, sea ice extents and ocean heat transports in a version of the Hadley Centre coupled model without flux adjustments, Climate Dyn., 16, 147-168.

Guilyardi, E., P. Delecluse, S. Gualdi and A. NAVARra (2002): The role of meridional recharging in ENSO phase change, J. Climate (in press).

HuRRELL, J.W. (1995): Decadal trends in the North Atlantic Oscillation: regional temperatures and precipitation, Science, 269, 676-679.
MANABE, S. and R.J. STOUFFER (1995): Simulation of abrupt climate change induced by freshwater input to the North Atlantic, Nature, 378, 165-167.

Manabe, S. and R.J. Stouffer (1999): The role of thermohaline circulation in climate, Tellus, 51, 91-109.

PeiXoto, J.P. and A.H. OORT (1993): Physics of Climate, American Institute of Physics, New York, pp. 520.

SARDEShMuKh, P.D. and B.J. Hoskins (1988): The generation of global rotational flow by steady idealized tropical divergence, J. Atmos. Sci., 45, 1228-1251.

SuTTON, R.T. and M.R. ALLEN (1997): Decadal predictability of North Atlantic sea surface temperature and climate, Nature, 388, 563-567.

SUTTON, R.T., W. A. NORTON and S.P. JEWSON (2001): The North Atlantic Oscillation - What role for the ocean?, Atmos. Sci. Lett., asle.2000.0018. 